\title{
Analysis of Rotor Position Detection Performance According to the Frequency of Square Waveform Voltage in the Harmonic Injection Sensorless Method through HILS
}

\author{
Kyeong-Rok Moon and Dong-Myung Lee *
}

Citation: Moon, K.-R.; Lee, D.-M. Analysis of Rotor Position Detection Performance According to the Frequency of Square Waveform Voltage in the Harmonic Injection Sensorless Method through HILS. Processes 2021, 9, 2267. https:// doi.org/10.3390/pr9122267

Academic Editor: Myung-Seop Lim

Received: 22 November 2021 Accepted: 15 December 2021 Published: 16 December 2021

Publisher's Note: MDPI stays neutral with regard to jurisdictional claims in published maps and institutional affiliations.

Copyright: (c) 2021 by the authors. Licensee MDPI, Basel, Switzerland. This article is an open access article distributed under the terms and conditions of the Creative Commons Attribution (CC BY) license (https:// creativecommons.org/licenses/by/ $4.0 /)$.
School of Electronic and Electrical Engineering, Hongik University, Seoul 04066, Korea; klmoon0201@naver.com * Correspondence: dmlee@hongik.ac.kr

\begin{abstract}
In this paper, the rotor position estimation performance of the sensorless scheme for permanent magnet synchronous motors (PMSMs) implemented through the injection of high-frequency square-wave voltage according to the frequency of the square-wave voltage is presented through HILS (Hardware In the Loop Simulation) experiments. An inverter using an IGBT device usually has a switching frequency of around $15 \mathrm{kHz}$. On the other hand, GaN devices that can be switched on and off at frequencies higher than $100 \mathrm{kHz}$ have been recently developed, and research is being actively conducted to apply GaNs to a variable speed system. The purpose of this study is to conduct HILS experiments to analysis the rotor position estimation ability of the sensorless technique in cases where a high switching frequency was applied, such as GaN devices, with that of a system having a usual switching frequency, such as IGBT. In the HILS system used in this study, an inverter and motor model implemented with Simulink are located in a real-time simulator. A sensorless motor control method was implemented with an FPGA control board, which includes a PWM interrupt service routine of $100 \mathrm{kHz}$ frequency and a harmonic injection and position detection algorithm. The HILS experiments show rotor position detection errors according to the various frequency of the harmonic voltage injected for estimating the rotor position with a PWM frequency of $100 \mathrm{kHz}$ cases. According to the experimental results, good position estimation was possible not only when the harmonic of $10 \mathrm{kHz}$ corresponding to $1 / 10$ of the PWM frequency was injected, but also when the harmonic of $1 \mathrm{kHz}$ corresponding to $1 / 100$ of the PWM frequency was injected. The experiments suggest that position estimation errors decrease as the frequency of the harmonic voltage increases, and, based on the foregoing, it is thought that the application of a GaN device capable of realizing a high switching frequency in a variable speed drive system can be another advantage.
\end{abstract}

Keywords: hardware-in-the-loop simulation (HILS); field programmable gate array (FPGA); square waveform voltage injection; sensorless control; rotor position estimation

\section{Introduction}

Due to the increase in electro-mobility, industrial applications of permanent magnet motors are expanding [1]. Permanent magnet motors are applied to various variable speed driving systems because their efficiency is higher compared to other motors and their output torque ratio per unit volume is excellent. In the vector control of general AC motors, a resolver or encoder is used for position detection, and a DSP is used to control the current and speed [2,3]. However, the position sensors of electric motors are vulnerable to external impacts so that they are damaged or deteriorated to the extent that they cannot work in some cases. To solve this problem, sensorless control techniques have been proposed [4-8]. In the case of the sensorless control of motors, the motors can be driven even without any position sensors such as encoders and resolvers so that the cost and system size are reduced, and reliability is enhanced because the risk of position sensor failure is reduced. However, a major disadvantage of sensorless motor control is that there are error values between actual motor information and estimated values. Therefore, sensorless systems 
cannot be used as main systems due to the limited performance of sensorless control, but there are cases where a sensorless control algorithm is used only as an emergency backup system when the position sensor does not operate normally or when it is out of order $[9,10]$.

Sensorless control techniques are largely divided into methods that use counter electromotive force and methods that apply high-frequency signals [11]. The square waveform harmonic injection sensorless control system enables easier estimation of positions than the existing counter-electromagnetic force estimation sensorless control technique at a low-speed region. At high and medium speeds, it can be used in combination with the counter-electromotive force sensorless control technique. In addition, it has the advantage that its efficiency is higher compared to the existing sinusoidal harmonic voltage injection technique because it has less noise and that it has fewer errors in angle estimation at low speeds compared to the counter-electromagnetic force sensorless technique. In this technique, a square harmonic voltage is injected into the current that is the output from the inverter and converted with the $d q$ coordinate system and the $q$-axis current of the current controller, and the position is estimated on the $d$-axis. If the frequency of the injected harmonic voltage is changed, the errors in the estimated angle and the estimated speed will be changed [12].

Meanwhile, studies on electric power converters applied with GaN devices that can switch at higher switching have been actively conducted recently. In addition, as shown in the simulation results in [12], the efficiency of the inverter differs by up to $6 \%$ according to the change in the switching frequency of the inverter using the GaN device and the Si device [13]. Thus, these electric power converters have higher efficiency than existing Si-based power semiconductors, and high dielectric breakdown fields, which enable highvoltage operation. Therefore, the system can be downsized due to lower heat generation and switching at higher speeds compared to the existing IGBT device. GaN devices are expected to bring about an improvement in inverter system control performance thanks to high-speed switching, as well as an improvement in physical aspects such as downsizing owing to a switching frequency not lower than $100 \mathrm{kHz}$.

Several papers on the sensorless control method using GaN have been published [14,15]. In [14], the sensorless control results at a $40 \mathrm{kHz}$ switching frequency using a matlab simulation were presented. Meanwhile, it is assumed that DSP is used for the controller. Although GAN is mentioned in [15], the actual inverter configuration uses $\mathrm{SiC}$ devices and shows position detection performance at a $40 \mathrm{kHz}$ switching frequency. Therefore, these two papers do not present the position detection characteristics at $100 \mathrm{kHz}$ switching frequency, which this study attempts to show, and do not contain information about HILS experiment.

A motor controller using an IGBT element usually has a switching frequency of around $15 \mathrm{kHz}$. Accordingly, the frequency of the harmonic waves injected in the existing harmonic injection sensorless technique is usually about $1 \mathrm{kHz}$, which is about $1 / 10$ of the PWM frequency. Therefore, in this paper, the effects of different frequencies of the harmonic waves injected for sensorless control in a system having a switching frequency of about $100 \mathrm{kHz}$ will be compared. That is, since the frequency of harmonic waves can be increased in cases where a GaN device is used, changes in the position estimation performance following the increase in the frequency will be shown.

\section{Square Waveform Harmonic Injection Sensorless Control and GaN FET}

Figure 1 is a block diagram of the control system of a permanent magnet synchronous motor (PMSM) with a speed sensor attached. The motor control system consists of a speed controller, a current controller, $d q$ transformation, and a space vector voltage pulse width modulation (SVPWM) subsystem. The speed controller outputs the command current through the PI controller using the speed command value and the measured speed. The current controller outputs the voltage reference using the output of the speed controller and the current value obtained by transforming the current measured through current transformers (CTs) into the $d q$ coordinate system. The output voltage is transformed 
again into $a b c$ coordinates to generate the gate signals through SVPWM, and the power semiconductor device switches to supply 3-phase AC power to the PMSM to operate.

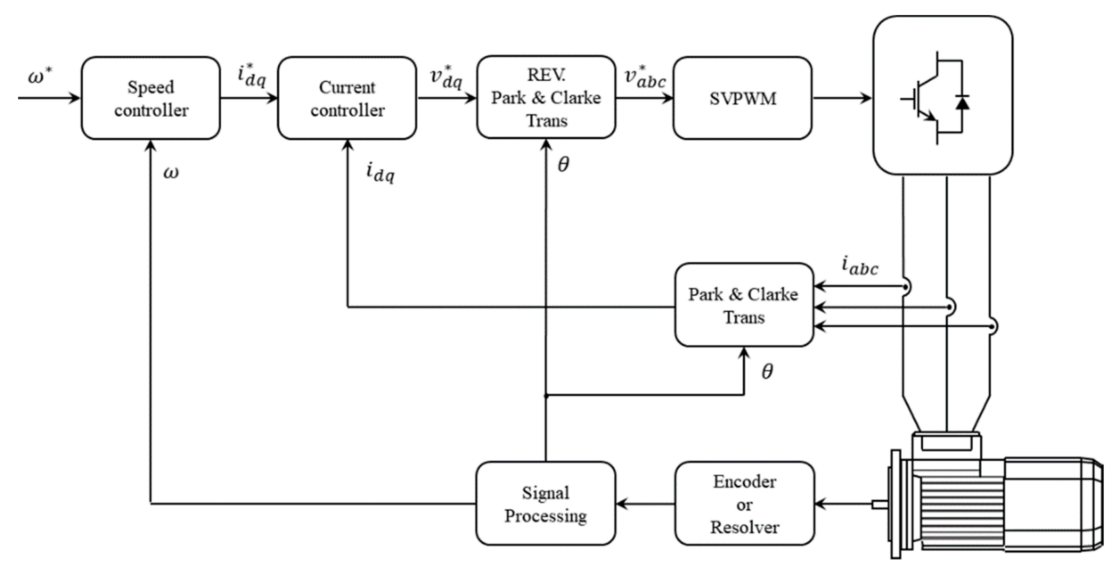

Figure 1. Block diagram of motor control system using sensors.

Figure 2 shows a diagram of the square harmonic voltage injection sensorless control system. Figure 3 displays a block diagram of motor position estimation. The harmonic voltage for estimating the position is applied to the $d$-axis, and from the harmonic current generated due to this, the harmonic part is extracted using a band stop filter (BSF) to estimate the position of the rotor. The square waveform injection sensorless scheme is described below. In the PMSM, since the stator resistance $\left(R_{s}\right)$ can be ignored because its size is smaller compared to the size of $j \omega_{h} L_{d q}$, the impedance of the motor is expressed as shown in Equation (1). Here, $\omega_{h}$ is the angular frequency of the harmonic, and $h$ stands for harmonic. The relationship between the harmonic voltage and the harmonic current is shown in Equation (2). Here, $R(\theta)$ denotes a matrix that transforms fixed coordinate system values into synchronous coordinate system values. In the equation, the superscript $s$ stands for the stationary reference frame and $r$ stands for the rotor reference frame.

$$
\begin{gathered}
{\left[z^{r}\right]=\left[\begin{array}{cc}
j \omega_{h} L_{d} & 0 \\
0 & j \omega_{h} L_{q}
\end{array}\right]} \\
{\left[\begin{array}{c}
v_{d s h}^{r} \\
v_{q s h}^{r}
\end{array}\right]=\left[z^{r}\right][R(\theta)]\left[\begin{array}{c}
i_{d s h}^{s} \\
i_{q s h}^{s}
\end{array}\right]}
\end{gathered}
$$

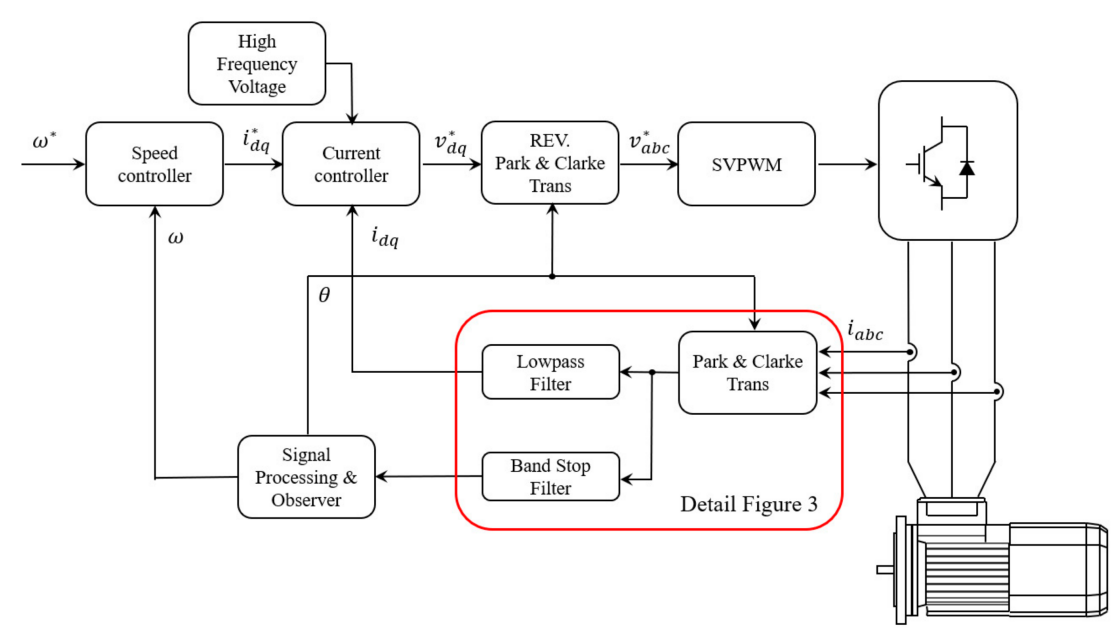

Figure 2. Schematic diagram of a sensorless motor control system using the square harmonic voltage injection technique. 


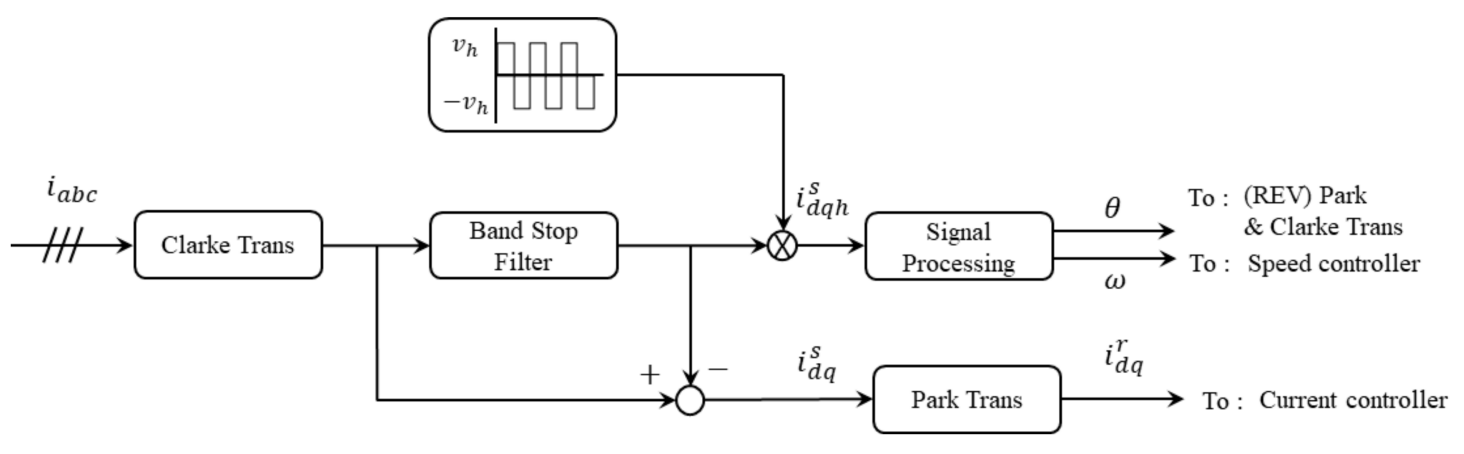

Figure 3. Block diagram of rotor angle estimation.

If Equation (2) is organized with $i_{d q s h}$, it will be as shown in Equation (3), where, if $\theta$, which is the actual position of the rotor, and $\hat{\theta}$, which is the estimated position obtained through the high-frequency voltage injection technique, are used, the foregoing can be expressed as shown in Equation (4).

$$
\begin{gathered}
{\left[\begin{array}{l}
i_{d s h}^{s} \\
i_{q s h}^{s}
\end{array}\right]=[R(\theta)]^{-1}\left[z^{r}\right]^{-1}\left[\begin{array}{c}
v_{d s h}^{r} \\
v_{q s h}^{r}
\end{array}\right]} \\
{\left[\begin{array}{c}
i_{d s h}^{s} \\
i_{q s h}^{s}
\end{array}\right]=[R(\theta)]^{-1}\left[z^{r}\right]^{-1}[R(\hat{\theta})]\left[\begin{array}{c}
v_{d s h}^{\hat{r}} \\
v_{q s h}^{r}
\end{array}\right]} \\
\hat{\theta}=\theta-\theta_{c a l}(\hat{\theta} \approx 0)
\end{gathered}
$$

$R(\theta)$ is shown in Equation (6), and if the inverse matrix of $R(\theta)$ and $z^{r}$ is obtained, substituted into Equation (4), and organized, Equation (7) can be obtained. In Equation (5), $\hat{\theta}$ means the error of the estimated rotor angle, and the angle error is assumed to be 0 degrees in the development of the equation hereafter.

$$
\begin{gathered}
{[R(\theta)]=\left[\begin{array}{cc}
\cos (\theta) & \sin (\theta) \\
-\sin (\theta) & \cos (\theta)
\end{array}\right]} \\
{\left[\begin{array}{c}
i_{d s h}^{s} \\
i_{q s h}^{s}
\end{array}\right]=\frac{v_{d q s h} \sin \left(\omega_{h} t\right)}{\omega_{h} L_{d}}\left[\begin{array}{c}
\cos (\theta) \\
\sin (\theta)
\end{array}\right]}
\end{gathered}
$$

Equation (7) expresses the relational expression of the injected harmonics and harmonic currents [16]. In Equation (7), it can be seen that $i_{d q s h}^{s}$ appears in the form of cosine and sine. Therefore, the rotor position can be estimated by taking the arc tangent to the harmonic $d$ - and $q$-axis currents as expressed in Equation (8) [17-19].

$$
\theta=\operatorname{atan} 2\left(i_{d s h}^{s}, i_{q s h}^{s}\right)
$$

Figure 4 is a conceptual diagram of the magnitude of the current generated in the $d$ - and $q$-axis magnetic flux paths corresponding to the harmonic voltage injected, and Figure 5 depicts the motor impedance corresponding to the injection position for each frequency of harmonic voltage [20]. When the harmonic voltage is injected into the $d$-axis, the impedance is minimized due to the phenomenon of saturation of the magnetic flux of the frequency corresponding to the harmonic voltage so that it becomes the position where the largest harmonic current for the same voltage occurs. This relationship applies equally to SPM and IPM. In the case of general inverters using an IGBT with a switching frequency of around $15 \mathrm{kHz}$, the frequency range of the voltage injected in previous studies is 200 to $1000 \mathrm{~Hz}$. This corresponds to about 1/50 to 1/10 of the PWM frequency. Since the power semiconductor used in this study is capable of $100 \mathrm{kHz} \mathrm{PWM}$, as with the GaN device, square waveform voltages in a range of $0.2 \sim 10 \mathrm{kHz}$ corresponding to $1 / 50 \sim 1 / 10$ of the 
switching frequency will be injected and the characteristics of rotor position detection will be investigated.

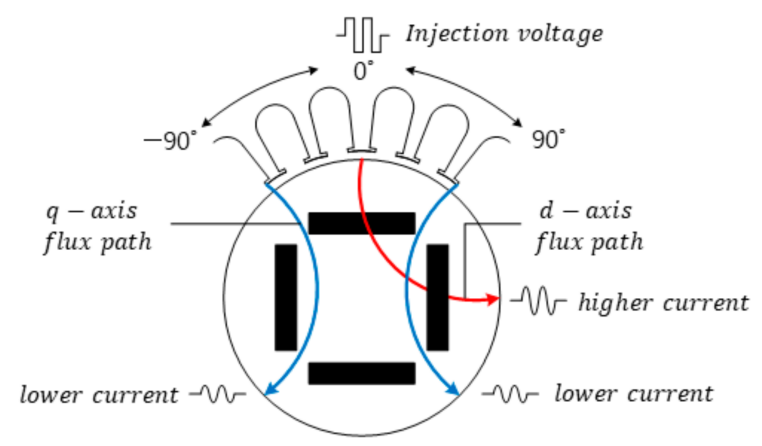

Figure 4. Conceptual diagram of changes in motor impedance according to the position of the motor when the harmonic voltage is applied.

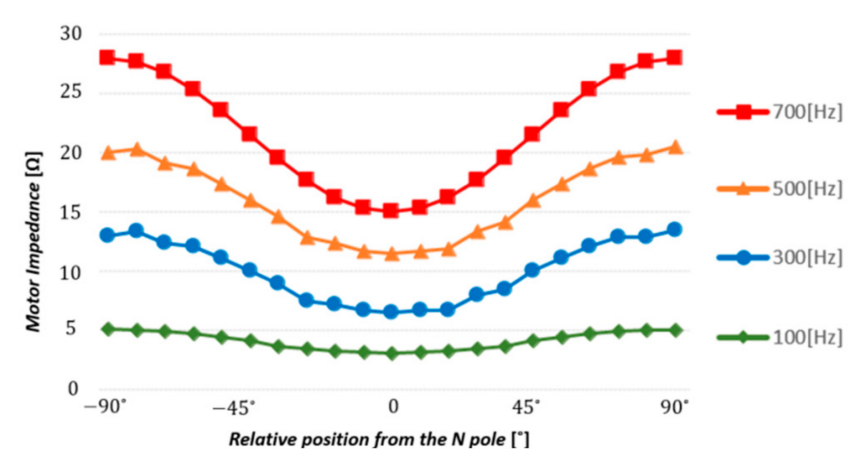

Figure 5. Impedance change curves according to the frequency of injection voltage.

For your reference, the characteristics of the GaN power transformation device and the silicon-based device are shown in Table 1. GaN devices have higher carrier movement speeds and lower breakdown voltages compared to silicon-based devices because they have the characteristics of wide bandgaps, high breakdown voltage, and low impedance. Therefore, when a GaN power transformation device is applied to an inverter, the thickness can be reduced more than that of a silicon-based power semiconductor because the dielectric breakdown field is large. Meanwhile, since the ban gap of $\mathrm{GaN}$ is wide, the efficiency of performance is not reduced even at relatively high temperatures. Therefore, when a power semiconductor device using $\mathrm{GaN}$ is used, the inverter can be downsized and has a high-power density [21-23].

Table 1. Characteristics of Si and GaN.

\begin{tabular}{ccc}
\hline Quantity & Si & GaN \\
\hline Band-gap $(\mathrm{eV})$ & 1.1 & 3.4 \\
Dielectric breakdown field $(\mathrm{MV} / \mathrm{cm})$ & 0.3 & 3.3 \\
Electron mobility $\left(\mathrm{cm}^{2} / \mathrm{VS}\right)$ & 2.5 & 10 \\
Thermal conductivity $(\mathrm{W} / \mathrm{cmK})$ & 1.5 & 1.3 \\
\hline
\end{tabular}

\section{Maltab/Simulink Model of Square Harmonic Injection Sensorless Technique}

Figure 6 is a sensorless control simulation model of PMSM using the square waveform harmonic voltage injection technique implemented with MATLAB/Simulink. In HILS experiments, this model is implemented using an FPGA control board. Individual subsystems indicated their respective controllers, and on comparison with the existing sensored control, it can be seen that a square waveform harmonic voltage injection block has been added. A PI controller is used for speed controller and current controller, and the space vector PWM uses the min-max method. 


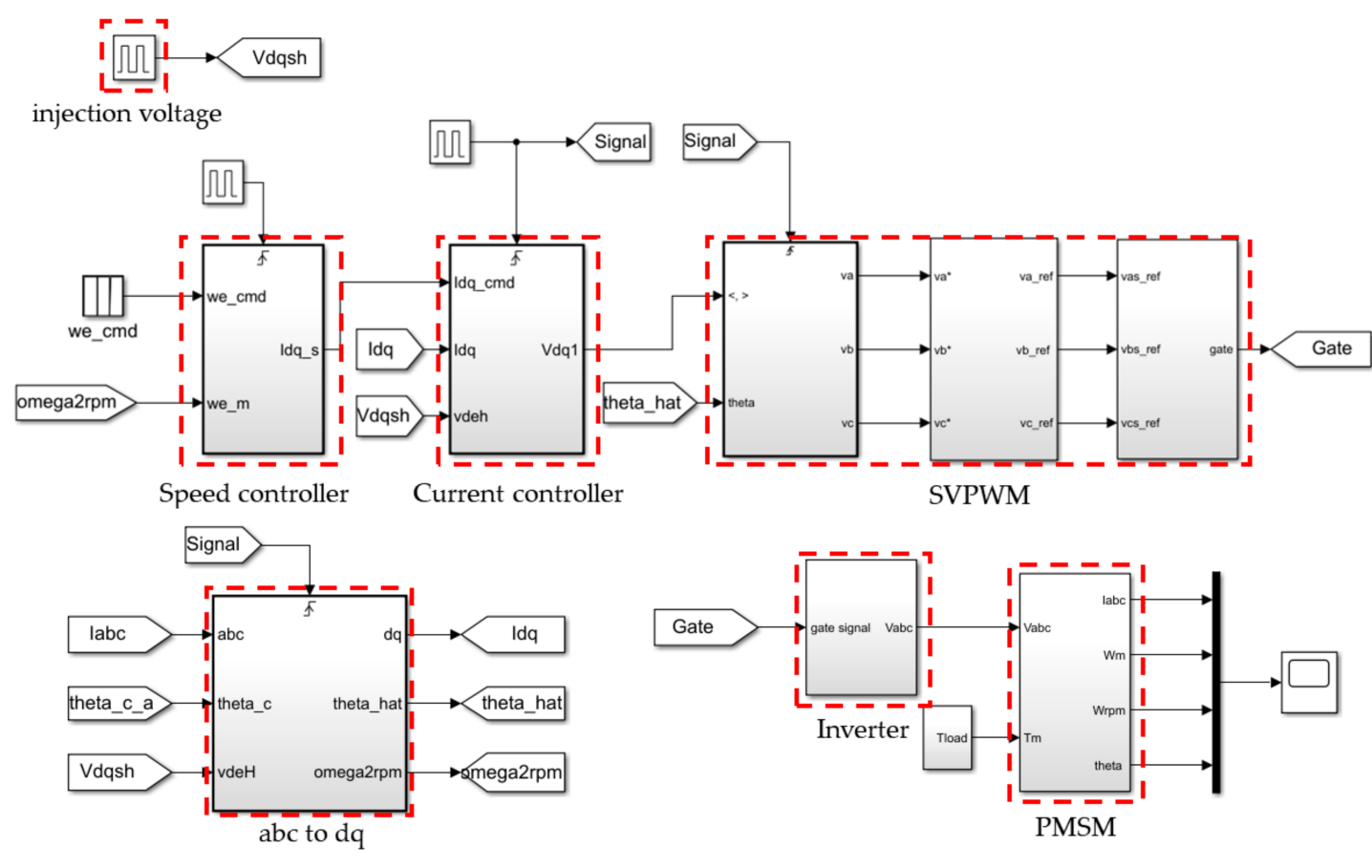

Figure 6. Sensorless motor control simulation model.

Figure 7 shows the blocks for estimating the rotor position and rotation speed. Figure 8 shows the internal configuration of the blocks in Figure 7. As shown in Figure 8, MATLAB function blocks were used for individual blocks to implement Equations (6)-(8) and bandstop filter (BSF). The filter part is implemented by discretizing the continuous terms, as done in [24]. The three-phase current containing harmonics is transformed into a two-phase current and passes through the BSF so that the harmonic part is detected, and the rotor position is estimated using the MATLAB function block that implemented Equation (7). LPF is used in measuring the phase currents to remove the harmonic current. The coefficient value of the BSF corresponds to the frequency of the injection voltage. In the case of Figure $7, f_{b p f}$ is $1 \mathrm{kHz}$, and $100 \mathrm{~Hz}$ was applied as the bandwidth (B). Table 2 shows the specifications of the motor used in the simulation. The ratio of $L_{d}$ and $L_{q}$ is 2 , and it is a setting to simulate the degree of saturation of harmonics following harmonic voltage injection.

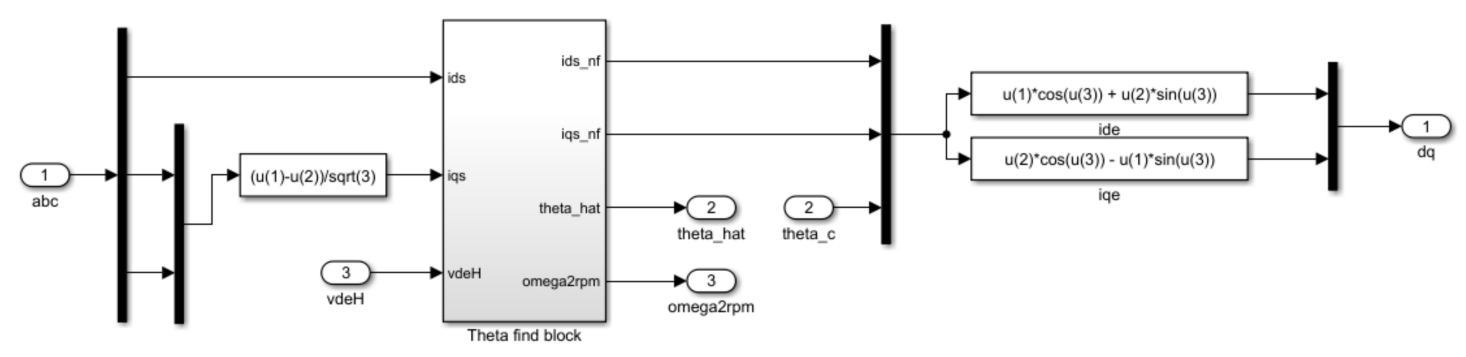

Figure 7. Rotor position detection and rotary coordinate system current detection blocks. 


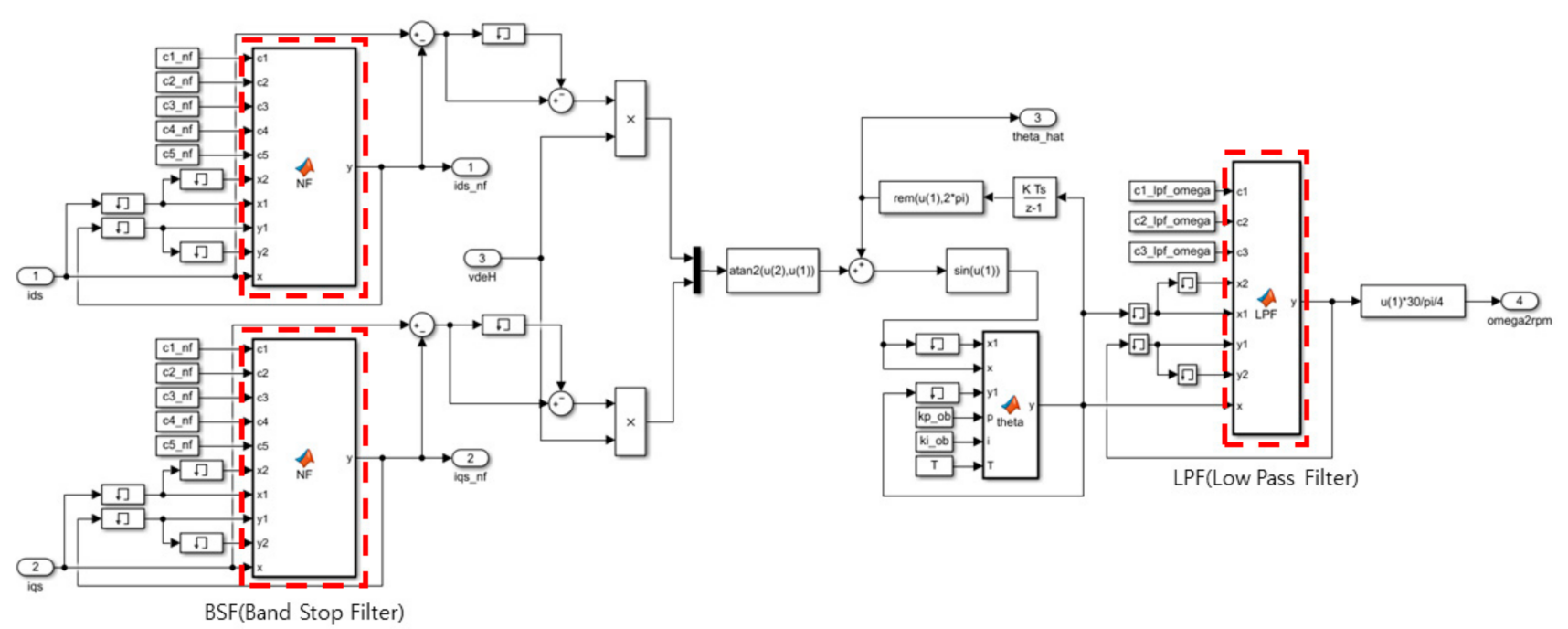

Figure 8. Rotor position detection model implemented with the MATLAB function block (Internal configuration of the subsystems shown in Figure 7).

Table 2. Specifications of the motor and system used in the simulation.

\begin{tabular}{ccc}
\hline Quantity & Comment & Value \\
\hline$R_{S}$ & Stator resistance & $0.15[\Omega]$ \\
$L_{d}$ & d-axis inductance & $3[\mathrm{mH}]$ \\
$L_{q}$ & q-axis inductance & $6[\mathrm{mH}]$ \\
$p$ & Number of poles & 8 \\
$P$ & Rated power & $1.5[\mathrm{~kW}]$ \\
$f_{S}$ & Switching frequency & $10[\mathrm{kHz}], 100[\mathrm{kHz}]$ \\
$f_{h}$ & Frequency of injection voltage & $0.2 \sim 1[\mathrm{kHz}], 0.2 \sim 10[\mathrm{kHz}]$ \\
$v_{h}$ & Magnitude of injection voltage & $\pm 2[\mathrm{~V}]$ \\
\hline
\end{tabular}

\section{Configuration of HILS Experimental Equipment and VHDL Program}

\subsection{Configuration of HILS Experimental Equipment}

Figure 9 shows the HILS configuration in this study. VHDL was used to implement the $100 \mathrm{kHz}$ PWM and sensorless algorithm, and the sensorless controller algorithm using harmonic injection was implemented in the FPGA controller. An inverter and a PMSM are modeled with Simulink and implemented in RT4510, a real-time simulator. The inverter and PMSM are operated in the real-time simulator, and the signals necessary for the controller are applied from the FPGA board. Meanwhile, the output from the control board to the real-time simulator is the gate signal of the inverter. The data designated by the user at the user PC are transmitted so that the user can monitor the system operation in HILs, and the resultant values are shown in a graph. In Figure 9, the flow diagram of the controller part is the same as the typical motor controller configuration.

Signal transmission between the real-time OS and DE1-SoC board, which is the control board, is as follows. The RT4510 transfers the motor current to the control board through the analog port, and this signal is connected to the ADC of DE1-SoC to detect the motor phase current value. Using this current, the sensorless algorithm derives a controller written in VHDL, which is a digital value, through the program. This digital value is connected to the gate signal of the inverter in the RT4510 through the digital port to generate a PWM signal. The resultant values of the experiment are sent to the user's PC using TCP/IP communication, and they are graphed and displayed on the monitor [25-27].

Figure 10 depicts a photo of the experimental equipment. Table 3 summarizes the names of individual devices. Device (3) is a board for matching the signal level between the control board (2) and real-time OS (1), and devices (4) and (5) are the power supply for 
board (3). Meanwhile, the parameters of the PMSM used in HILS experiments are the same values as those used for the MATLAB simulation as shown in Table 2.

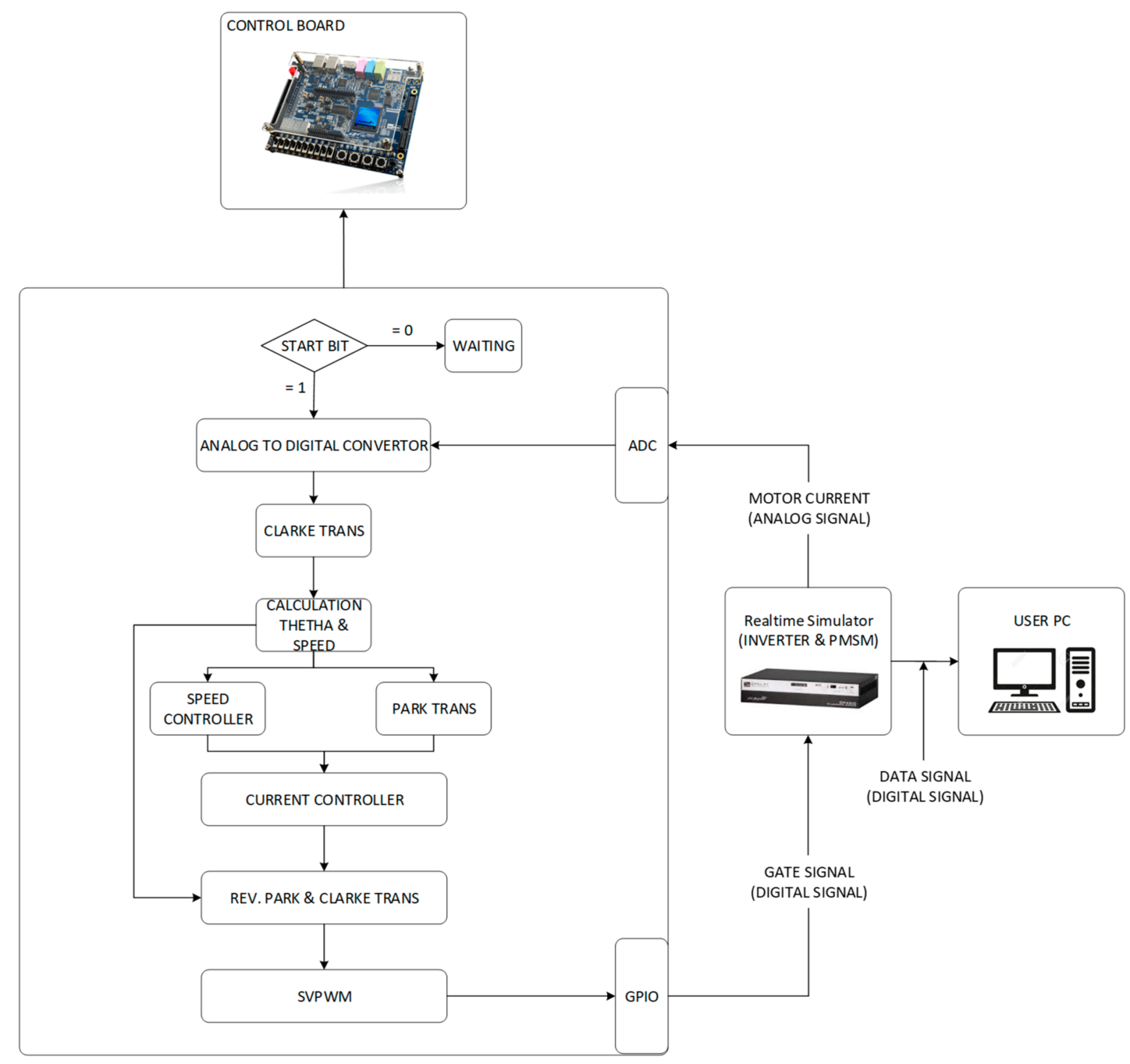

Figure 9. Block diagram of HILS experiment.

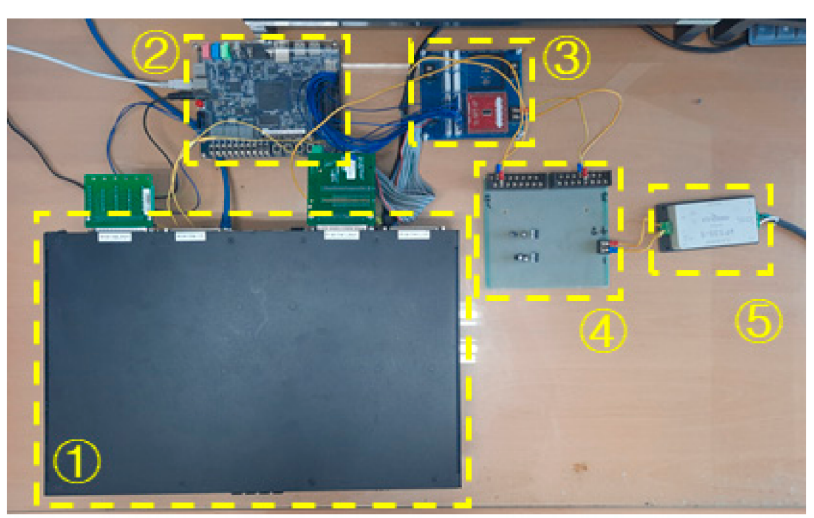

Figure 10. Photo of the configuration of the experiment. 
Table 3. Names of the hardware units constituting the experimental equipment shown in Figure 10.

\begin{tabular}{cc}
\hline Number & Name \\
\hline (1) & OP4510 (Real-time OS) \\
$(2)$ & DE1-SoC (Control board) \\
$(3)$ & Signal voltage level change board \\
$(4)$ & 3.3 volt regulator \\
(5) & 220 volt to 5 volt converter \\
\hline
\end{tabular}

\subsection{Controller Implementation Using FPGA}

In this section, the configuration of the FPGA program and the implementation of the arc tangent in Equation (7) to obtain rotor information are described. In this experiment, the DE1-SoC board from Terasic Co. was used. The Altera Cyclone ${ }^{\circledR}$ 5CSEMA5F31C6N was used on this board. The controller was designed using Verilog HDL through Altrera Co.'s Tool Quartus II. To receive the current value, which is an analog waveform, the analog-to-digital converter (ADC) of LTC2308 built in DE1-SoC was used. The ADC has 12-bit resolution, and since, unlike DSP, FPGA performs horizontal instead of vertical operation, each controller was implemented as a state machine.

As illustrated in Figure 11, the sections were composed of a total of five level controllers: initial state, ADC state, $d q$ state, speed-control state, and current-control state. In the initial state, the controller is in the standby state, and operates when an input is received. When the operation in each controller is finished, the start signal of the next controller is generated and the controller operates. When a series of operations is completed, the controller returns to the initial state and executes the series of operations again. If the RESET signal is input, all operations will be stopped regardless of which state the controller is in, and the operation will return to the initial state so that the controller waits for operation.

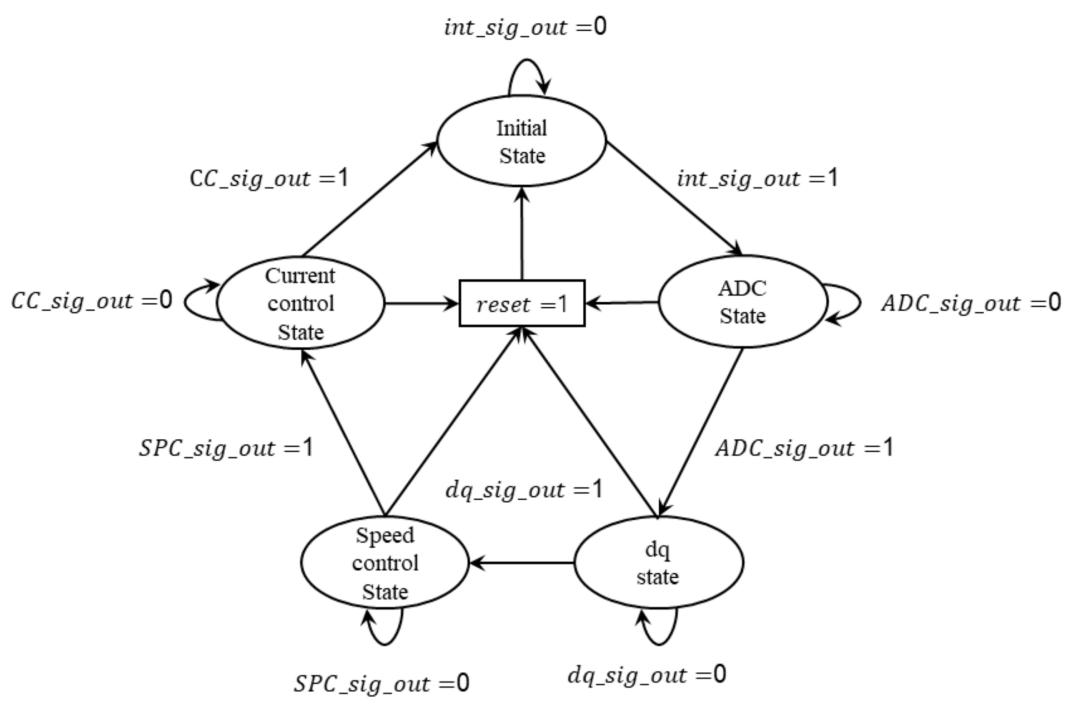

Figure 11. State machine of controller in FPGA.

\subsection{Arc Tangent Calculation Using VHDL}

To obtain the position of the motor in Equation (7), the arc tangent should be calculated, and this is done using a lookup table. To utilize the limited memory space, a lookup table is constructed for values corresponding to $0^{\circ}$ to $45^{\circ}$, and values corresponding to other angles are calculated through the characteristics of atan (arc tangent) values in eight areas as shown in Figure $12[28,29]$. The data sheet for atan IP core used in the Quartus prime tool is provided by Inter Co., and information about the atan IP core is provided in the data sheet. The adaptive lookup tables (ALUTs) that store atan 2 values of the atan IP core store 2454 data. Since the atan 2 interpolation method used in this study uses 450 data for each of 
the ALUTs, and the number of data corresponding to eight sectors is 3600 . Therefore, it outputs more accurate data than the atan IP core [30].

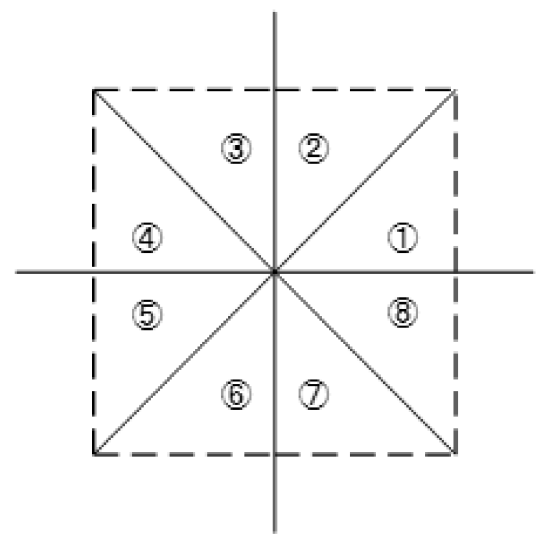

Figure 12. Eight sectors divided for arc tangent calculation.

Interpolation was applied to calculate median values. Interpolation uses the fact that when a tangent value of $0^{\circ}$ to $45^{\circ}$ is multiplied by 100 , sequential values from 1 to 100 are derived as approximate values. As shown in Figure 12, angles were divided into eight sectors, and the calculation of each sector produced the values stored in the $45^{\circ}$ atan 2 lookup table as summarized in Table 4 . Therefore, $360^{\circ}$ of arc tangents can be expressed through calculations using $45^{\circ}$ lookup tables by sector. Here, $x$ corresponds to the $q$-axis harmonic current component, and $y$ corresponds to the $d$-axis harmonic current component. The data were stored in the lookup tables, and the sizes of the required values were retrieved from the lookup tables by calculation. In the table, $\theta^{\prime}$ are angles corresponding to $0^{\circ}$ to $45^{\circ}$, and $\theta$ are angles ranging from $0^{\circ}$ to $360^{\circ}$ estimated using $45^{\circ}$ data.

Table 4. Angle value calculation formulas according to the sector.

\begin{tabular}{cccc}
\hline Condition & Sector & $\theta^{\prime}$ & $\theta$ \\
\hline$x \geq 0$ & $(1)$ & $\frac{y}{x}$ & $\theta^{\prime}$ \\
$y \geq 0$ & $(2)$ & $\frac{y}{x}$ & $90-\theta^{\prime}$ \\
\hline$x<0$ & $(3)$ & $\frac{y}{x}$ & $90+\theta^{\prime}$ \\
$y \geq 0$ & $(4)$ & $\frac{y}{x}$ & $180-\theta^{\prime}$ \\
\hline$x \leq 0$ & $(5)$ & $\frac{y}{x}$ & $180+\theta^{\prime}$ \\
$y \leq 0$ & 6 & $\frac{y}{x}$ & $270-\theta^{\prime}$ \\
\hline$x>0$ & $(7)$ & $\frac{y}{x}$ & $270+\theta^{\prime}$ \\
$y \geq 0$ & 8 & $\frac{y}{x}$ & $360-\theta^{\prime}$ \\
\hline
\end{tabular}

Figure 13a,b displays the codes that were implemented. Each figure illustrates the arc tangents implemented by calculation for each quadrant as shown in Table 4 . A total of 100 lookup tables were constructed, and the formula for each sector is shown in Table 4. In the figure, tan_cal_d and tan_cal_q are the currents $\left(i_{d q s h}\right)$ in the state where the injection voltage was applied through the BSF, and tan_cnt is the address to find the data specified in the lookup table. When absolute values are taken for the sine and cosine values, the $|\cos (\theta)|$ and $|\sin (\theta)|$ values have the range of $45^{\circ}$ and the large and small ones are changed. Through the foregoing, each quarter was divided by $45^{\circ}$ to create eight areas. As shown in the codes by sector, the value of the numerator and the denominator were determined using the formulas in Table 4. In addition, when the value of one of $\cos (\theta)$ and $\sin (\theta)$ is negative, the value is multiplied by -1 so that only positive values are output as the values of tan_cnt. Since the LUTs value stored in advance is output after multiplying the tan_cnt value by 100 , atna 2 is implemented by interpolation. 


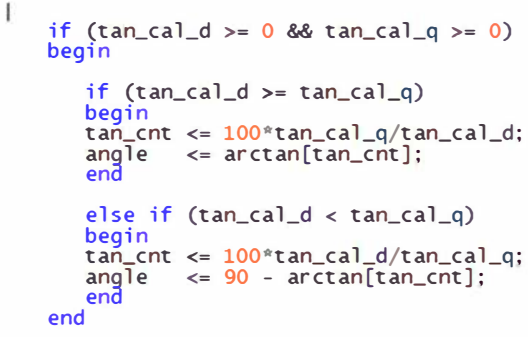

(a)

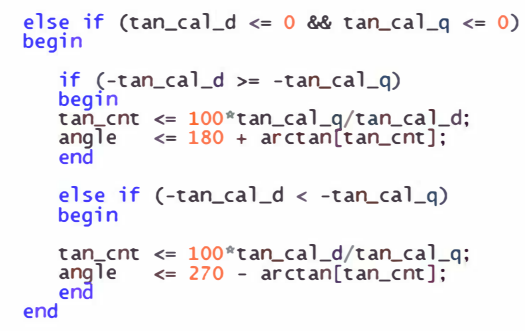

(c)

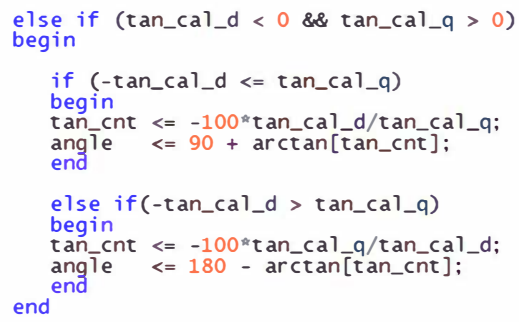

(b)

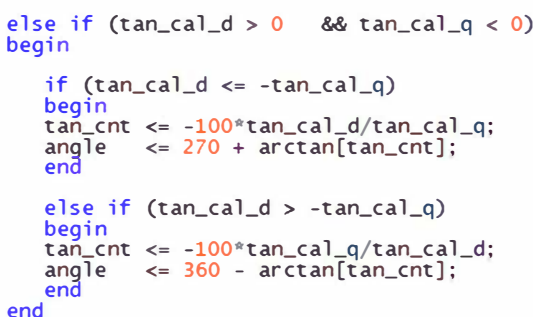

(d)

Figure 13. Verilog HDL code for angle calculation: (a) angle calculation code in 1-Quadrant, (b) angle calculation code in 2-Quadrant, (c) angle calculation code in 3-Quadrant, (d) angle calculation code in 4-Quadrant.

\section{Experimental Results}

Through experiments, the rotor position detection performance of sensorless techniques for $200 \mathrm{~Hz} \sim 10 \mathrm{kHz}$ high-frequency injection voltage is examined when the PWM frequency is $100 \mathrm{kHz}$ as with $\mathrm{GaN}$ devices. Figure 14 shows representative waveforms appearing when harmonics are injected. Figure 14a depicts the phase a current of the motor. Figure $14 \mathrm{~b}$ shows that harmonics were added in the terminal voltage waveform. Figure $14 \mathrm{c}$,d displays the $d$-axis and $q$-axis harmonic component current HILS experimental waveforms that passed through the BSF.

In the experiment, the rotation speed command value $\left(n^{*}\right)$ is $200 \mathrm{rpm}$. In Figures 15 and 16, the PWM switching frequencies are $f_{s w 1}=10 \mathrm{kHz}$ and $f_{s w 2}=100 \mathrm{kHz}$, respectively. The waveforms in Figures 15 and 16 are the experimental waveforms when the frequencies of the injected harmonic voltage are $200-2000 \mathrm{~Hz}$ and $200-10,000 \mathrm{~Hz}$, respectively. In the case of a system with a $10 \mathrm{kHz}$ switching frequency, the maximum frequency of the injection voltage frequency was $2 \mathrm{kHz}$, and in the case of a GaN device capable of $100 \mathrm{kHz}$ switching, the experiments were conducted while increasing the frequency of the injection voltage up to $10 \mathrm{kHz}$.

It can be seen that the errors in the angle estimation vary according to the magnitude of the frequency of the harmonic voltage, and that in cases where $f_{s w 1}=10 \mathrm{kHz}$, the error rate between the estimated speed and the command speed becomes larger when the frequency of the injection voltage becomes smaller or larger than $1 \mathrm{kHz}$. In cases where the switching frequency was $f_{s w 2}=100 \mathrm{kHz}$, the command speed was followed well when the frequency of the harmonics was $10 \mathrm{kHz}$. It can be seen that the error in the estimated rotor angle was smaller than cases where the switching frequency was $f_{s w 1}=10 \mathrm{kHz}$. In Figure 15, the red waveform (indicated by $\theta_{-} x_{-}$real) is the actual position of the rotor, and the blue solid line (indicated by $\theta \_x \_c a l$ ) is the estimated position where $x$ denotes the corresponding frequency of the injection voltage. In each waveform, the figure on the left shows the command speed and the calculated speed, and the figure on the right shows the estimated rotor angle and the actual rotor angle waveforms. The left figure of Figure 16d shows that the speed has a lot of ripple. That means the operating state of the motor is very unstable when operating at the $2 \mathrm{kHz}$ injection frequency.

In Figure 16, it can be clearly seen that when the switching frequency is $100 \mathrm{kHz}$, as the injection frequency increases $(200 \mathrm{~Hz} \rightarrow 500 \mathrm{~Hz} \rightarrow \ldots \rightarrow 10 \mathrm{kHz})$, that is, as figures are switched from Figure $16 \mathrm{a} \rightarrow$ Figure $16 \mathrm{~b} \rightarrow \ldots \rightarrow$ Figure 16e, the error in the rotor 
angle estimation is reduced. Looking at the right figure of Figure 16e, it is obvious that the position error is almost zero. As shown in Figure 5, as the frequency of the voltage increases, the ratios of the magnitudes of the impedance between the $d$-axis and the $q$-axis show a shape closer to sine, and this is thought to be the reason why the position estimation error is reduced.

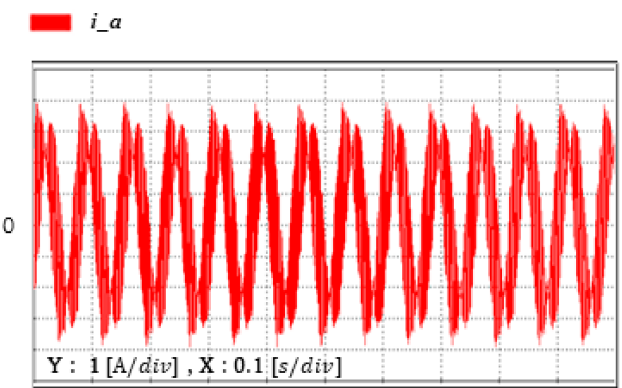

(a)

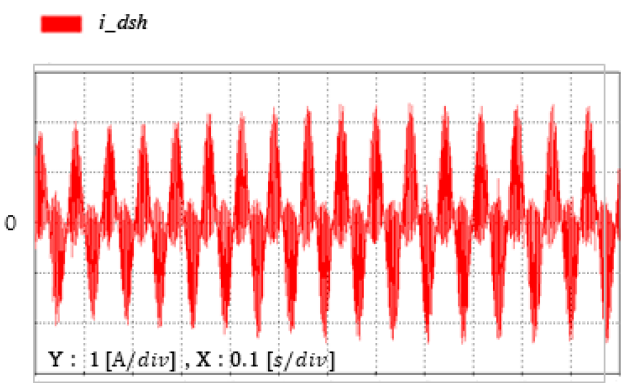

(c)

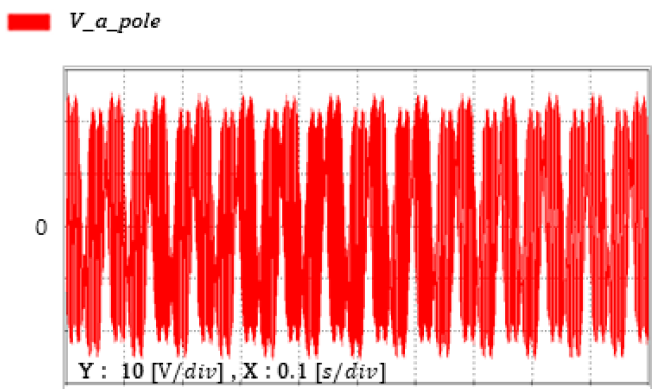

(b)

$i_{-} q s h$

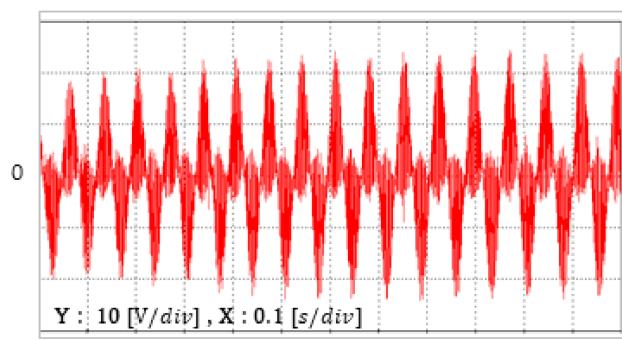

(d)

Figure 14. Representative voltage and current waveforms when harmonic voltages are injected: (a) 3-phase current, (b) pole voltage, (c) $d$-axis harmonic current, and (d) $q$-axis harmonic current.

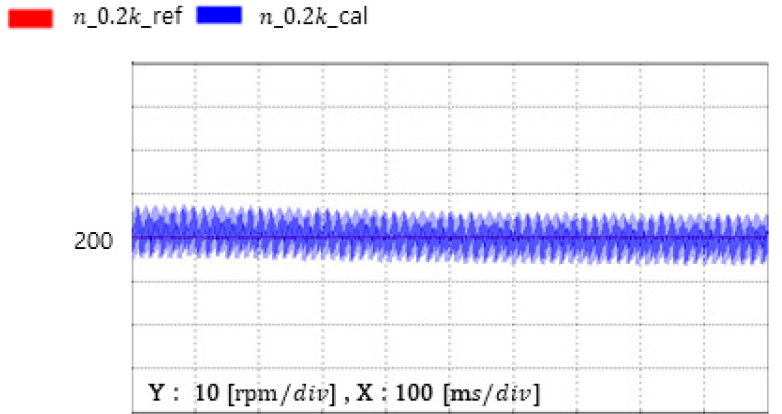

$n_{-} 0.5 k_{-}$ref

$n_{-} 0.5 k_{-} \mathrm{cal}$

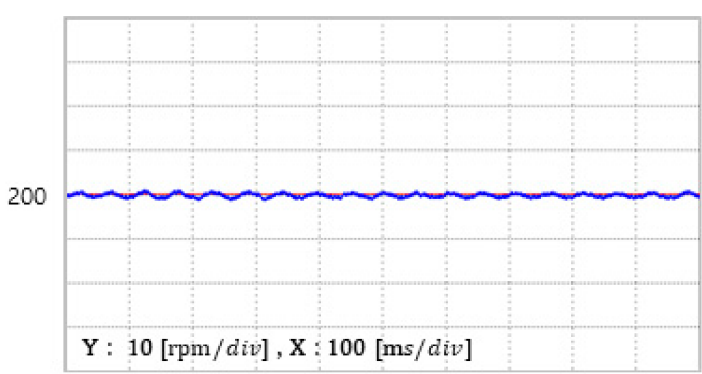

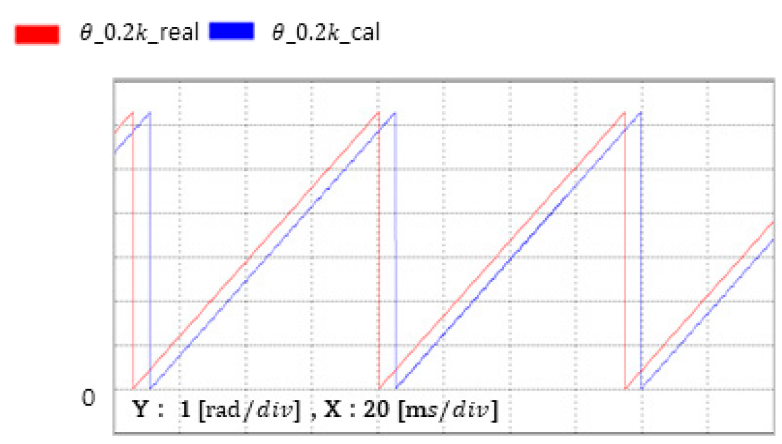

(a)

$\theta_{-} 0.5 k_{-}$real $\theta_{-} 0.5 k_{-}$cal

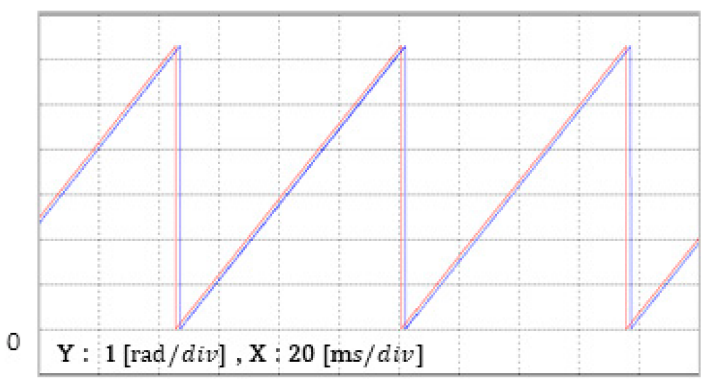

(b)

Figure 15. Cont. 
$n_{-} 1 k_{-}$ref

$n_{-} 1 k_{-} \mathrm{cal}$

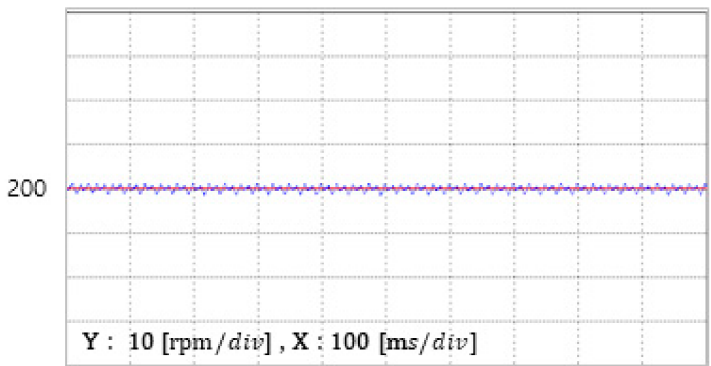

(c)

$n_{-} 2 k_{-}$ref $n_{-} 2 k_{-}$cal

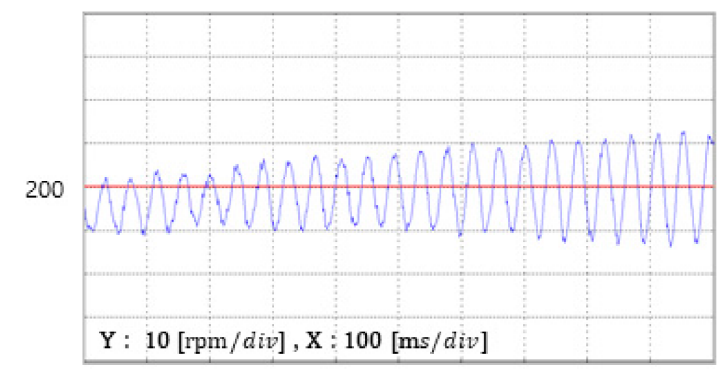

$\theta_{-} 1 k_{-}$real $\theta_{-} 1 k_{-}$cal

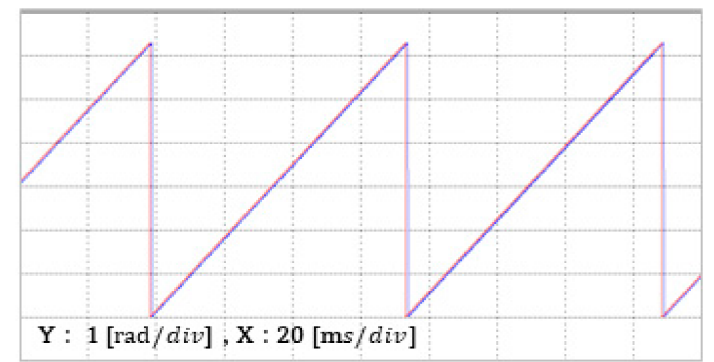

$\theta_{-} 2 k_{-}$real $\theta_{-} 2 k_{-}$cal

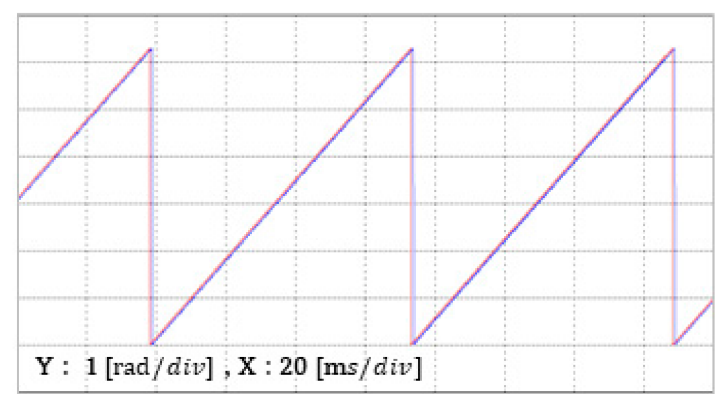

(d)

Figure 15. Waveforms resulting from HILS experiments according to changes in the frequency of the injected harmonic when the PWM frequency is $10 \mathrm{kHz}$ : The frequencies of injection voltages are (a) $0.2 \mathrm{kHz},(\mathbf{b}) 0.5 \mathrm{kHz}$, (c) $1 \mathrm{kHz}$, and (d) $2 \mathrm{kHz}$.

$n \_0.2 k_{-}$ref $n \_0.2 k_{-}$cal

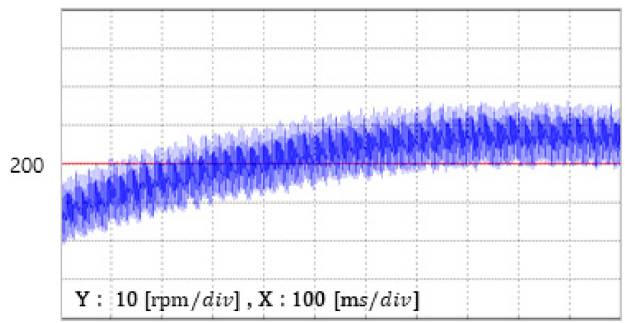

$n \_0.5 k_{-}$ref

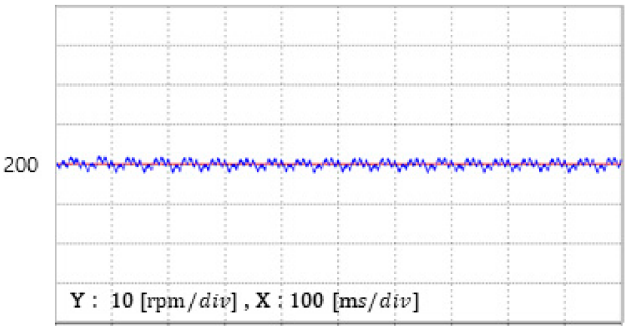

$\theta_{-} 0.2 k_{-}$real $\theta_{-} 0.2 k_{-}$cal

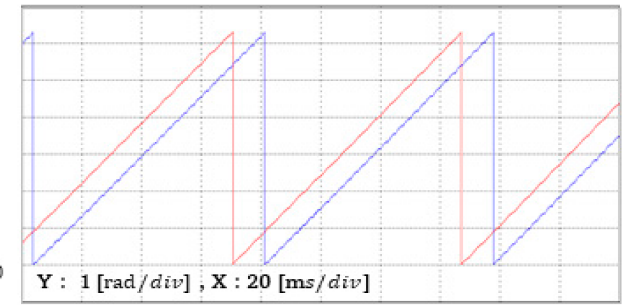

(a)

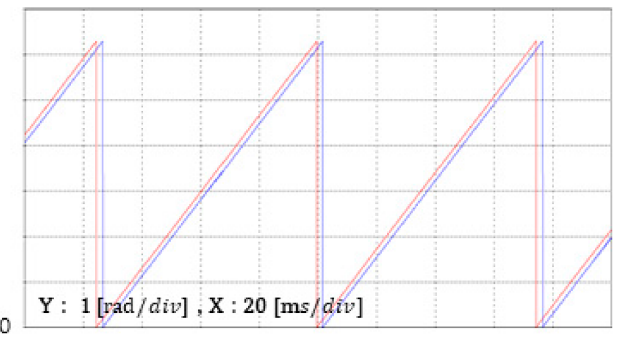

(b)

Figure 16. Cont. 
n_1 $k_{-}$ref $n \_1 k_{-}$cal

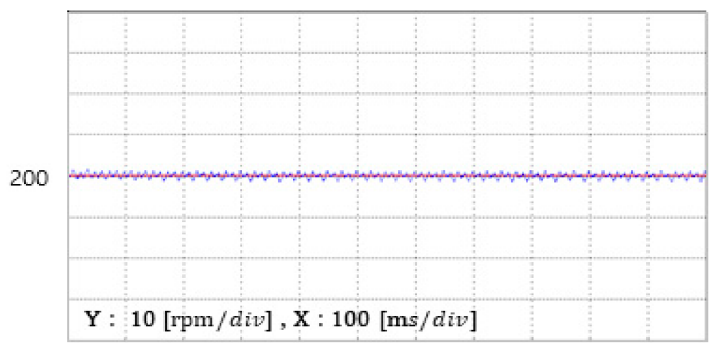

$n_{-} 2 k_{-}$ref

$n \_2 k_{-}$cal

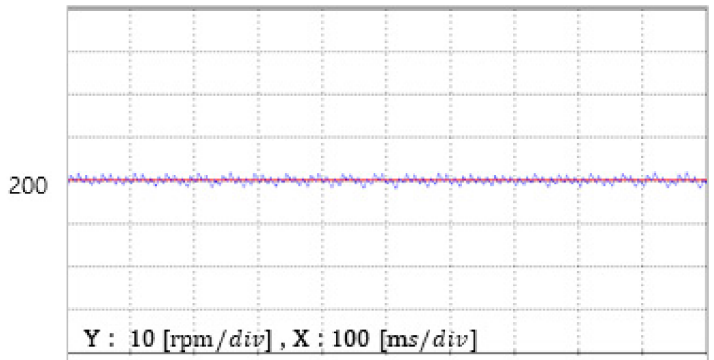

$n_{-} 10 k_{-}$ref

$n_{-} 10 k_{-} \mathrm{cal}$

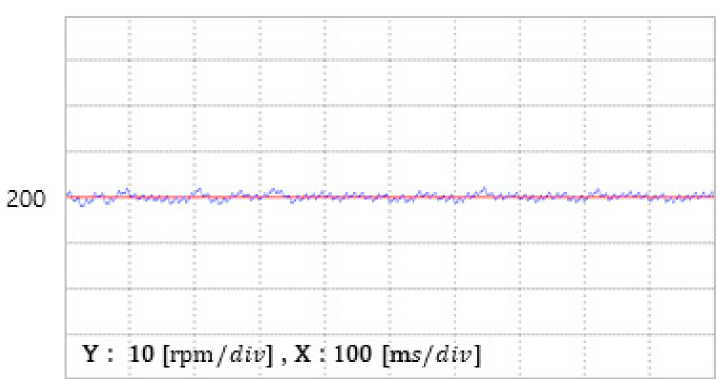

$\theta_{-} 1 k_{-}$real

$\theta_{-} 1 k_{-} c a l$

0

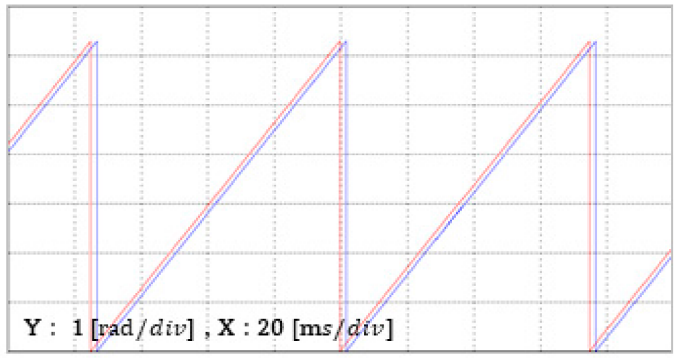

(c)
$\theta \_2 k_{-}$real
$\theta \_2 k_{-}$cal

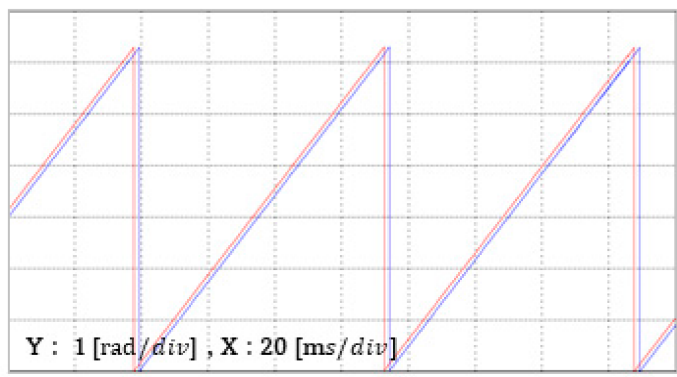

(d)
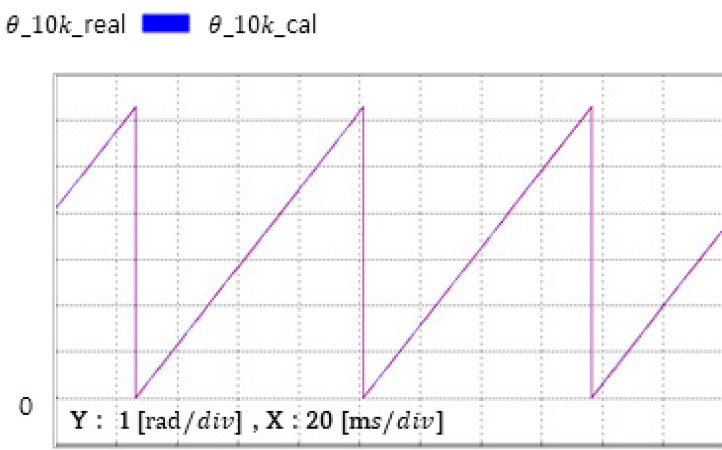

(e)

Figure 16. Waveforms resulting from HILS experiments according to changes in the frequency of the injected harmonic when the PWM frequency is $100 \mathrm{kHz}$ : the frequencies of injection voltages are (a) $0.2 \mathrm{kHz},(\mathbf{b}) 0.5 \mathrm{kHz},(\mathbf{c}) 1 \mathrm{kHz},(\mathbf{d}) 2 \mathrm{kHz}$, and (e) $10 \mathrm{kHz}$ (in each waveform, the figure on the left shows the command speed and the calculated speed, and the figure on the right shows the estimated rotor angle and the actual rotor angle).

The $x$-axis is the frequency of the injection voltage, and the $y$-axis is $\Delta \theta\left(\theta_{\text {real }}-\theta_{\text {cal }}\right)$, which is measured at the moment when the actual angle of the rotor was changed from $2 \pi$ radian to 0 radian. In the case of $10 \mathrm{kHz} P W M$, when the injection voltage frequency was $2000 \mathrm{~Hz}$ or higher, the angle error is $25.2^{\circ}$, indicating that the sensorless motor control was unstable. Therefore, there is no position error result for the $10 \mathrm{kHz}$ injection voltage frequency because the speed control of the motor is not possible in the case of $10 \mathrm{kHz}$ PWM.

In contrast, in the case of $100 \mathrm{kHz}$ PWM, there is a position estimation error result even for an injection harmonic of $2 \mathrm{kHz}$ or higher. As clearly shown in Figure 17, the position estimation performance in the case of $2000 \mathrm{~Hz}$ harmonic injection was shown to be better at $100 \mathrm{kHz}$ PWM case. Furthermore, it can be seen that if $10,000 \mathrm{~Hz}$, that is, $10 \mathrm{kHz}$, voltage is injected, the position estimation error becomes smaller. Meanwhile, the position estimation performances when $500 \mathrm{~Hz}$ and $1000 \mathrm{~Hz}$ harmonics were injected in the case of $100 \mathrm{kHz}$ PWM were shown to be the same as those in the case of $10 \mathrm{kHz}$ PWM. 


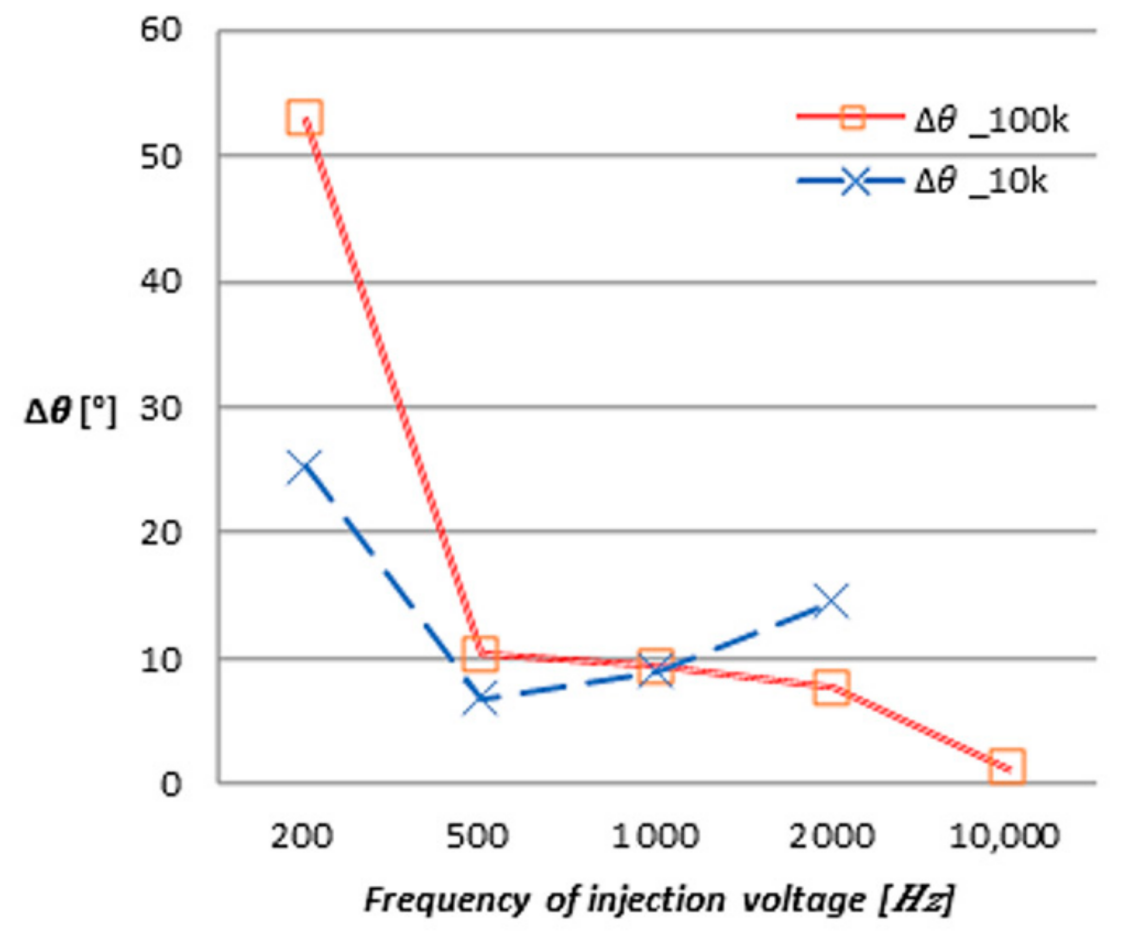

Figure 17. Position estimation errors according to harmonic voltage frequency in the cases of $10 \mathrm{kHz}$ and $100 \mathrm{kHz}$ PWM.

\section{Conclusions}

In this study, the motor position estimation performance of the sensorless method carried out through the application of harmonic voltage with a frequency of about $1 / 10$ of the switching frequency in an inverter system, which normally has $10 \mathrm{kHz}$ switching frequency, was compared and experimented with the sensorless motor position control performance according to the frequency of the injected harmonic voltage in a system with high switching frequency, which is about $100 \mathrm{kHz}$, as with GaN using HILS system. To implement a $100 \mathrm{kHz}$ PWM interrupt service routine for systems with high switching frequencies as with $\mathrm{GaN}$ devices, a sensorless technique was implemented with FPGA, and the ability of the sensorless technique to estimate rotor positions was shown through the HILS experiment. In addition, in the arc tangent calculation for position estimation, a method of calculating the $0-360$ degree sector using only 0-45 degree data in the FPGA was described.

The fact that the estimation error decreases as the injection voltage frequency increases in a system with a high switching frequency, such as a GaN device, was shown through the HILS experiments. The effect of increase in the frequency of the injection voltage in the sensorless technique in a system with a high frequency of $100 \mathrm{kHz}$ in comparison with a system with a switching frequency of around $15 \mathrm{kHz}$ was shown. In summary, when the frequency of the injection voltage was increased to $200 \mathrm{~Hz}, 500 \mathrm{~Hz}, 1 \mathrm{kHz}, 2 \mathrm{kHz}$, and $10 \mathrm{kHz}$ at the $100 \mathrm{kHz}$ switching frequency, the position detection error started at $52.08^{\circ}$ and decreased to $10.25^{\circ}, 9.34^{\circ}, 7.62^{\circ}$, and $1.26^{\circ}$, respectively. For the injection voltage having a frequency of $10 \mathrm{kHz}$, the rotor position error was only $1.26^{\circ}$. From these experimental results, it can be inferred that the reduction in the rotor position error is due to the fact that the change in inductance according to the position becomes more sinusoidal compared to the low frequency as the frequency of the harmonic voltage increases. As a result, it is thought that the application of a GaN device capable of realizing a high switch frequency in a variable speed drive system can be one of other advantages. In addition, the derivation of these results shows the efficacy of the technique using the HILS system in the development of sensorless control system. 
Author Contributions: Conceptualization K.-R.M. and D.-M.L.; software, K.-R.M.; validation, K.-R.M. and D.-M.L.; investigation, K.-R.M. and D.-M.L.; writing—original draft preparation, K.-R.M.; writing—review and editing, D.-M.L.; project administration, D.-M.L.; funding acquisition, D.-M.L. All authors have read and agreed to the published version of the manuscript.

Funding: This research received no external funding.

Institutional Review Board Statement: Not applicable.

Informed Consent Statement: Not applicable.

Data Availability Statement: Not applicable.

Acknowledgments: This research was supported by Basic Science Research Program through the National Research Foundation of Korea (NRF) funded by the Ministry of Science, ICT and Future Planning (NRF-2021R1A2C1005782).

Conflicts of Interest: The authors declare no conflict of interest.

\section{References}

1. Zwerger, T. A Control Scheme for PMSMs using Model Predictive Control and a Feedforward Action in the Presence of Saturated Inputs. In Proceedings of the 2021 22nd International Carpathian Control Conference (ICCC), Velké Karlovice, Czech Republic, 31 May-1 June 2021; pp. 1-6.

2. Zbede, Y.B.; Gadoue, S.M.; Atkinson, D.J. Model Predictive MRAS Estimator for Sensorless Induction Motor Drives. IEEE Trans. Ind. Electron. 2016, 63, 3511-3521. [CrossRef]

3. Vollmer, M.U.; Kennel, R. Demodulation Approach for Slowly Sampled Sensorless Field-oriented Control Systems Enabling Multiple-frequency Injections. Ind. Appl. Soc. Ann. Meet. 2016, 54, 1-9.

4. Sul, S.K.; Kwon, Y.C.; Lee, Y. Sensorless Control of IPMSM for Last 10 Years and Next 5 Years. CES Trans. Electron. Mach. Syst. 2017, 1, 91-99. [CrossRef]

5. Lee, K.W.; Ha, J.I. Evaluation of Back-EMF Estimators for Sensorless Control of Permanent Magnet Synchronous Motors. J. Power Electron. 2012, 12, 604-614. [CrossRef]

6. Xu, D.; Wang, B.; Zhang, G.; Wang, G.; Yu, Y. A review of Sensorless Control Methods for AC motor Drives. CES Trans. Electr. Mach. Syst. 2018, 2, 104-115. [CrossRef]

7. Lee, K.W. High-speed Sensorless Control of a PMSM Operating under Periodic Magnetic Saturation Conditions. In Proceedings of the 2014 IEEE Energy Conversion Congress and Exposition (ECCE), Pittsburgh, PA, USA, 14-18 September 2014; Volume 15, pp. $4478-4483$.

8. Hong, C.H.; Lee, J.; Lee, D.M. Sensorless Scheme for Interior Permanent Magnet Synchronous Motors with a Wide Speed Control Range. J. Power Electron. 2016, 16, 2173-2181. [CrossRef]

9. Filho, C.J.V.; Xiao, D.; Vieira, R.P.; Emadi, A. Observers for High-Speed Sensorless PMSM Drives: Design Methods, Tuning Challenges and Future Trends. IEEE Access 2021, 9, 56397-56415. [CrossRef]

10. Makino, S.; Kakihara, M.; Takase, Y.; Takaki, M.; Shikayama, T.; Ohto, M.; Higuchi, T.; Abe, T. Development of a Stator-Magnetless Linear Synchronous Motor for Sensorless Control. IEEE Trans. Ind. Appl. 2017, 53, 4559-4568. [CrossRef]

11. Bae, B.H.; Sul, S.K.; Kwon, J.H.; Byeon, J.S. Implementation of Sensorless Vector Control for Super-high-speed PMSM of Turbo-compressor. IEEE Trans. Ind. Appl. 2003, 39, 811-818. [CrossRef]

12. Lee, W.; Han, D.; Sarlioglu, B. GaN-based Single phase Brushless DC Motor Drive for High-speed Applications. In Proceedings of the IECON 2014-40th Annual Conference of the IEEE Industrial Electronics Society, Dallas, TX, USA, 29 October-1 November 2014; Volume 61, pp. 1499-1505.

13. Lee, W.; Kim, J.H.; Choi, W.; Sarlioglu, B. Torque Ripple Minimization via PWM Control Technique with GaN-based Motor Drive for High Speed Single phase Brushless DC motor. In Proceedings of the 2015 IEEE Energy Conversion Congress and Exposition (ECCE), Montreal, QC, Canada, 20-24 September 2015; pp. 4019-4025.

14. Wang, Z.; Li, J.; Wang, H.; Cheng, H.A. GaN Drive for Ultra-High-Speed Permanent Magnet Synchronous Motor. In Proceedings of the 2020 23rd International Conference on Electrical Machines and Systems (ICEMS), Hamamatsu, Japan, 24-27 November 2020; pp. 1040-1045.

15. Walden, J. High Frequency Injection Sensorless Control for a Permanent Magnet Synchronous Machine Driven by an FPGA Controlled SiC Inverter. Master's Thesis, University of Tennessee Knoxville, Knoxville, TN, USA, 2021.

16. Kim, J.; Jeong, I.; Nam, K.; Yang, J.; Hwang, T. Sensorless Control of PMSM in a High-speed Region Considering Iron Loss. IEEE Trans. Ind. Electron. 2015, 62, 6151-6159. [CrossRef]

17. Yoon, Y.; Sul, S.; Morimoto, S.; Ide, K. High-Bandwidth Sensorless Algorithm for AC Machines Based on Square-Wave-Type Voltage Injection. IEEE Trans. Ind. Appl. 2011, 47, 1361-1370. [CrossRef]

18. Han, B.; Shi, Y.; Song, X.; Hong, K.; Mao, K. Initial Rotor Position Detection Method of SPMSM Based on New High Frequency Voltage Injection Method. IEEE Trans. Power Electron. 2019, 34, 3553-3562. [CrossRef] 
19. Kim, S.; Ha, J.; Sul, S. PWM Switching Frequency Signal Injection Sensorless Method in IPMSM. IEEE Trans. Ind. Appl. 2012, 48, 1576-1587. [CrossRef]

20. Kang, J. Sensorless Control of Permanent Magnet Motors. Control. Eng. 2010, 57, 1-4.

21. Mishra, U.K.; Parikh, P.; Wu, Y.F. AlGaN/GaN HEMTs-an Overview of Device Operation and Applications. Proc. IEEE 2002, 90, 1022-1031. [CrossRef]

22. Shah, F.M.; Xiao, H.M.; Awais, R.; Zhou, G. Comparative Performance Evaluation of Temperature Dependent Characteristics and Power Converter using GaN, SiC and Si Power Devices. In Proceedings of the 2018 IEEE 12th International Conference on Compatibility, Power Electronics and Power Engineering (CPE-POWERENG 2018), Doha, Qatar, 10-12 April 2018 ; pp. 1-7.

23. Tsao, J.Y.; Chowdhury, S.; Hollis, M.A.; Jena, D.; Johnson, N.M.; Jones, K.A.; Kaplar, R.J.; Rajan, S.; Van de Walle, C.G.; Bellotti, E.; et al. Ultrawide-Bandgap Semiconductors: Research Opportunities and Challenges. Adv. Electron. Mater. 2018, 4, 1600501. [CrossRef]

24. Yoon, J.W.; Lee, D.M. Simulation Model of Harmonics Injection Sensorless Technique for Permanent Magnet Synchronous Motor. J. KAIS 2020, 24, 67-71.

25. Shin, D.C.; Lee, D.M. Development of Real-time Implementation of a Wind Power Generation System with Modular Multilevel Converters for Hardware in the Loop Simulation using Matlab/Simulink. Electronics 2020, 9, 606. [CrossRef]

26. Fathy, H.K.; Filipi, Z.S.; Hagena, J.; Stein, J.L. Review of Hardware in the Loop Simulation and its Prospects in the Automotive Area. Proc. SPIE 2006, 6228, 1-20.

27. Cho, J.; Choi, D.; Yoo, S.; Lee, W.; Stein, J.L. PC-based Real-time Driving Simulation. In Proceedings of the Korea Society for Simulation Conference, Daejeon, Korea, 11 November 2000; pp. 192-197.

28. Lyons, R. Another Contender in the Arc Tangent Race. IEEE Signal. Proc. Mag. 2004, 21, 109-110. [CrossRef]

29. Ukil, A.; Shah, V.H.; Deck, B. Fast Computation of Arctangent Functions for Embedded Applications: A Comparative Analysis. In Proceedings of the 2011 IEEE International Symposium on Industrial Electronics, Gdansk, Poland, 27-30 June 2011; pp. 1206-1211.

30. Intel. ALTERA_CORDIC IP Core User Guide. Available online: www.intel.com/content/www/us/en/products/programmable. html (accessed on 8 May 2017). 